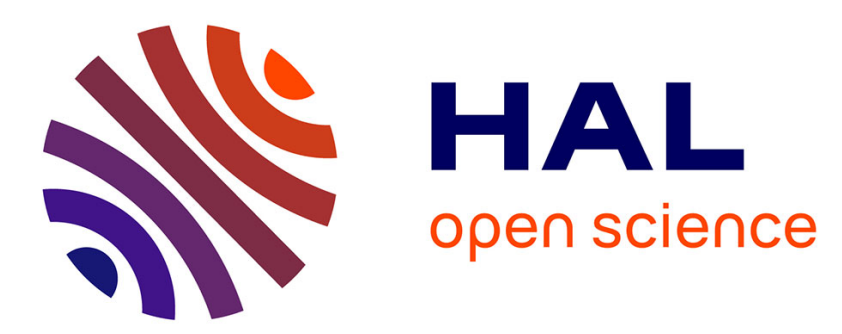

\title{
Relative Age Effect in Female Sport: A Diachronic Examination of Soccer Players
}

\author{
Nicolas Delorme, Julie Boiché, Michel Raspaud
}

\section{To cite this version:}

Nicolas Delorme, Julie Boiché, Michel Raspaud. Relative Age Effect in Female Sport: A Diachronic Examination of Soccer Players. Scandinavian Journal of Medicine and Science in Sports, 2010, 20 (3), pp.509-515. 10.1111/j.1600-0838.2009.00979.x . hal-00383125

\section{HAL Id: hal-00383125 \\ https://hal.science/hal-00383125}

Submitted on 24 May 2010

HAL is a multi-disciplinary open access archive for the deposit and dissemination of scientific research documents, whether they are published or not. The documents may come from teaching and research institutions in France or abroad, or from public or private research centers.
L'archive ouverte pluridisciplinaire HAL, est destinée au dépôt et à la diffusion de documents scientifiques de niveau recherche, publiés ou non, émanant des établissements d'enseignement et de recherche français ou étrangers, des laboratoires publics ou privés. 
Relative Age Effect in Female Sport: A Diachronic Examination of Soccer Players

Running head: RAE in French Female Soccer

This is a preprint version of the paper. For the final published version, please go to: http://www3.interscience.wiley.com/journal/122499151/abstract 


\begin{abstract}
The Relative Age Effect (RAE) is a biased distribution of elite athletes' birthdates, with an over-representation of those born at the beginning of the competitive year and an under-representation of those born at the end. Despite an abundant literature, the impact of sex on this phenomenon remains neglected by most researchers. This study investigated the whole sample of female soccer players affiliated to the French Soccer Federation for the 2006-2007 season $(n=57,892)$. It first aimed at testing the presence of RAE depending on age. Next, we looked at the birthdates of dropout players during the next season $(n=15,285)$, to test whether relative age accounts for dropout from the activity. The analyses revealed significant differences between the expected and observed distributions for all age categories. Furthermore, a significantly biased distribution of dropout players' birthdates was found for the less than 10, less than 14 and less than 17 categories. As a whole, dropout players are under-represented in Q1 and Q2, but over-represented in Q3 and Q4. This study completes the literature on RAE among females, but the inconsistency of the results calls for more research on this population.
\end{abstract}

Key words: Relative age effect, female, soccer, dropout. 


\title{
Relative Age Effect in Female Sport: A Diachronic Examination of Soccer Players
}

\author{
Introduction
}

The Relative Age Effect (RAE) is a phenomenon initially observed by Grondin, Deshaies and Nault (1984), and consists in a biased distribution of elite players' birthdates. What is generally noticed is an over-representation of athletes born at the beginning of the competitive year but an under-representation of people born at the end of it. It is considered to derive from the age categories distinguished by sport instances to organise and try to balance youth competition. Most of the time, children and adolescents born during two consecutive years are gathered in a common category. Thus, within a system using the first of January as cut-off date, a child born in January of the first year of a category will show a discrepancy of up to 23 months with a child born in December of the second year. This difference in relative age is likely to induce important variations in terms of physical (Tanner \& Whitehouse, 1976) and cognitive development (Bisanz, Morrisson \& Dunn, 1995), the discrepancies being particularly marked during puberty (Delorme \& Raspaud, 2009). The advantages regarding physical characteristics (i.e., in height, weight or strength) can undoubtedly impact those young players' perceived potential in the activity (Helsen, Van Winckel \& Williams, 2005). Those born at the beginning of the competitive year are more easily identified as "talented" or "promising", and consequently, they are more often selected to be part of elite groups or to play within national youth teams. They benefit from this early exposition that may bring them determinant technical and strategic skills (Williams, 2000; Ward \& Williams, 2003).

This differentiated access to high level training and competition is considered as a kind of discrimination, since it disadvantages players born late after the cut-off date, reducing drastically their chances to access to the elite (Musch \& Hay, 1999; Simmons \& Paull, 2001; Edgar \& O'Donoghue, 2005). Even if such discrimination seems involuntary, it needs to be 
examined cautiously, given the profits that can be achieved through the practice of certain sports.

\section{RAE and Dropout}

In addition to partly conditioning the access to high-level practice, the differences of experience induced by relative age are likely to be a factor of dropout for the young participants born late in the competitive year. First, because of a less advanced physical development, they might experience a reduced time of play during official games, as suggested by the study of Vaeyens, Philippaerts and Malina (2005). Additionally, relative age may be accompanied by divergences in terms of self-perceptions. Indeed, players born at the end of the competitive year may encounter more frequent situations of failure or inferiority, and such negative situations are likely to undermine those players' feelings of competence and self-worth.

Past literature in sport psychology reveals that reduced opportunities to play (Guillet et al., 2002), as well as low perceptions of sport competence significantly contribute to the cessation of the practice of team sports (Ommundsen \& Vaglum, 1991a, 1991b; Guillet et al., 2006). Thus, the RAE traditionally observed among elite samples could also be the result of more important rates of dropout among players born late in the competitive year. In this vein, [Authors] show that among male basketball players aged between 9 and 15 years old, and female players aged from 8 to 15 years, those born in the end of the year are over-represented among dropout players, whereas those born early after the cut-off date are under-represented. Such a biased distribution in the birthdates of dropout players also emerged among male soccer players aged from 8 to 17 years old [Authors].

\section{Competition and RAE}

Even if the role of the cut-off date chosen to create age categories among young participants is deemed central in the RAE phenomenon, it is not considered as the only 
necessary condition for its presence. Instead, in their review of the literature, Musch and Grondin (2001) present it as the result of "a mixture of physical, cognitive, emotional, and motivational causes work together to produce the effect" (p. 159). The first element they underline is competition. Indeed, in the case of a low competition, any player can belong to the team and may benefit from numerous opportunities to play, because there is a place for everyone. As the authors advance, "the larger the pool of potential players, for a given sport in a given category, the strongest the resulting RAE should be" (p. 154). In this vein, if the number of potential players is superior to the actual structures (i.e., number of teams, number of players in a team) and infrastructures (i.e., equipment available and time slots), there will be an accrued competition between them to belong to a team. In these conditions, the priority will be given to the more performing players, potentially those born early in the competitive year, who benefit from a better perception from coaches regarding their potential in the activity, compared to players born later in the year (Helsen et al., 2005).

This said, it is logical to expect a RAE to appear in popular activities, which is subject to cultural disparities (i.e., the popularity of one sport varies from one country to another). For instance, in Canada, a RAE was systematically observed for ice-hockey (e.g., Barnsley, Thompson \& Barnsley, 1985; Barnsley \& Thompson, 1988; Grondin \& Trudeau, 1991), which represents the most popular activity in this country, whereas no effect was observed for volleyball (Grondin et al., 1984), a low developed sport. Some authors also underlined the link between the strength of the RAE and the level of practice studied in a given sport: the more the level increases, the stronger the RAE. This correlation has particularly been shown in ice-hockey and soccer (Musch \& Grondin, 2001).

Factors of Success in the Activity and RAE

The second main factor underlined by Musch and Grondin (2001) is the prevalence of physical attributes for performance in the activity. Most of the studies in which a RAE was 
observed concerned activities in which height, weight, and strength represent key factors of success, like team sports involving physical contact such as ice-hockey (e.g., Grondin \& Trudeau, 1991), football (e.g., Daniel \& Janssen, 1987), soccer (e.g., Helsen et al., 1998), or other individual activities, like tennis or swimming (Baxter-Jones, 1995). Conversely, in other activities, the physical attributes cited can be seen as relatively independent from success, because other parameters, such as motor skills, are more prevalent, or can even be seen as counter-productive, because being short and thin is preferable for performance. This is the case for example for dance or gymnastics, which should thus not be prone to a RAE. Accordingly, Van Rossum (2006) did not find RAEs among Dutch dancers. This hypothesis was also sustained by the work of Baxter-Jones and Helms (1996) and of Malina, Bouchard and Bar-Or (2004), who showed that a late puberty was an advantage for young dancers and gymnasts. Besides, a positive correlation was found between a late puberty and elite gymnastics practice (Baxter-Jones et al., 1995; Malina, 1994).

\section{Sex and RAE}

Musch and Grondin (2001) stated that stronger RAEs should be observed in male youth sports, compared to female samples. According to Baxter-Jones (1995), such differences would result from a complex interaction between the biological differences due to puberty and sociological factors. In fact, when considering the two factors presented above, as sport represents a masculine area, competition is expected to be higher among boys than girls, leading to a greater RAE (Musch \& Grondin, 2001). Indeed, if an early physical development gives an important advantage to young sportsmen in many activities, it appears to be a disadvantage for young sportswomen, given the existing social pressures around their body (Vincent \& Glamser, 2006). This stereotyped representation of the female body may lead early developed girls to drop out from sports activities (Shakib, 2003), reducing that way the potential strength of the RAE. Finally, because of an earlier puberty in girls, and the bigger 
variance in the development of puberty in boys, at the moment of the selection process, there would be greater physical disparities due to relative age among boys, compared to girls (Baxter-Jones, 1995).

However, in spite of an abundant literature on this phenomenon in the sport setting, the impact of sex remains neglected by most researchers (Musch \& Grondin, 2001; Wattie et al., 2007). Studies concerning female samples are not only scarce to date, but they revealed inconsistent results. To our knowledge, only five studies concerned the examination of RAE in female samples. Two of them concerned popular activities, i.e., where an important competition should enhance RAE, but where physical attributes are considered as handicapping or at least not advantageous, namely gymnastics and dance. Baxter-Jones (1995), studying elite British gymnasts, observed no RAE neither for males or females. Van Rossum (2006) reached the same conclusions with pre-professional Dutch dancers.

Conversely, the three other studies concerned team sports were a RAE was traditionally observed among male athletes. First, Delorme, Boiché and Raspaud (in press), investigating French elite championships in team sports, report no RAE for female soccer, basketball and handball players, whereas several significant effects emerged for male players in ice hockey and trends were observed for rugby union and handball. In the same vein, Vincent and Glamser (2006), analysing a sample of 17-year American soccer players, report a more systematic and stronger RAE for males, compared to females. Finally, Delorme and Raspaud (2009) observed a significant RAE in all youth categories of French basketball players, aged from 7 to 17 years. The effects were even more pronounced for girls compared to boys. Those results suggest that among female adult, elite samples, there is actually no or weak RAEs. However, the only study conducted on regular young sport participants reveals a significant effect for both girls and boys.

Purpose of the Study and Hypotheses 
Given those contradictory results and the reduced number of studies having investigated female athletes in the past, it seems crucial to look at original samples of this population in order to better understand the impact of sex on the occurrence of RAE. With this regard, the purpose of the present study was twofold. Investigating the female soccer players affiliated to the French Soccer Federation (FSF) for the 2006-2007 season, it first aimed at examining the presence or absence of RAE depending on age. This was made by looking at every age category in a diachronic perspective. Next, we looked at the birthdates of the players that had not reiterated their affiliation for the 2007-2008 season, in order to test whether relative age account for female dropout from the activity.

Given the previous research discussed above, the two following hypotheses are formulated:

1) We expect a systematic RAE in all youth age categories but no effect in the adult category.

2) We expect an over-representation of late-born children in dropout and an under-representation of those who are born early in the competitive year for each youth category. Concerning the adult category, a uniform distribution of dropouts is expected.

$$
\text { Materials and methods }
$$

\section{Data Collection}

For the purpose of the present study, the bithdates of all French female players affiliated to the FSF $(n=57,892)$ during the 2006-2007 season were collected from the federation database. Among this sample the FSF also communicated the birthdates of the players that did not reiterate their affiliation for the 2007-2008 season $(n=15,285)$. This information was communicated after the 2007-2008 season was over, so as to avoid considering as dropout players that had taken their licence late during the season. Among 
female players, the FSF distinguishes 6 age categories: "less than 8 years", "less than 10 years", "less than 12 years", "less than 14 years", "less than 17 years" and "adults".

\section{Data Analysis}

In past literature, the presence of a RAE is determined by showing a significant difference between the expected number of players born by month or quarter (i.e., three consecutive months period) and the observed distribution. For each of the 6 categories presented, the players' birthdates were classified into 4 quarters. Since the cut-off date used to form age categories has been modified by the FSF (Jullien, Turpin \& Carling, 2008), the players born before 1982 were classified from Q1 (August-October) to Q4 (May-July) and the players born in 1982 and after were classified from Q1 (January-March) to Q4 (OctoberDecember).

A chi-square goodness-of-fit test was then performed, comparing the expected and observed distribution of birthdates. In line with previous research, for each age category, the expected distribution was calculated based on the national birth statistics by month and year for females, using weighted mean scores. Those data were obtained through the National Institute of Economical Statistics and Studies. Regarding dropout players, the expected distribution considered was based on the birthdates observed for the whole population of females licensed soccer players by month and year, using weighted mean scores. For this type of analysis, this procedure is deemed more adequate than the use of national standards for comparison [Authors].

\section{Results}

Table 1 presents the birthdates' distribution by quarter for each age category identified for female players by the FSF, during the 2006-2007 season. 
****Please insert Table 1 approximately here****

The analyses reveal statistical differences between expected and observed distributions for all age categories. For all youth categories the results reflect a classical RAE with an overrepresentation of players born in Q1 and Q2, and an under-representation of players born in Q3 and Q4. For the "adult" category, however, the asymmetry observed derived from this classical pattern: players born in Q2 and Q4 are over-represented, but those born in Q1 and Q3 were under-represented.

Table 2 presents the rates of dropout for each age category for the 2006-2007 season.

****Please insert Table 2 approximately here****

The dropout rate increases in the first age categories and from the "less than 12 years" and on it approximates $30 \%$. The general turnover rate is equal to $26,4 \%$.

Table 3 presents the birthdates distribution by quarter of dropout players for the 20062007 season, for each age category.

****Please insert Table 3 approximately here****

A significantly biased distribution was found for the less than 10 , less than 14 , and less than 17 categories. As a whole, dropout players are under-represented in Q1 and Q2, but more often over-represented in Q3 and Q4. Conversely, the birthdate distribution was distributed as expected for the less than 8 , less than 12 , and adult categories.

\section{Discussion}


A relative age effect (RAE) has traditionally been observed among male athletes of elite level in sports where physical attributes such as weight, height and strength represent key factors for success. This phenomenon can thus be seen as the consequence of a selection bias favouring players born at the beginning of the competitive year and potentially higher rates of dropout among players born at the end. Very little is known about RAE among female athletes, and the handful of studies that investigated this population report heterogeneous results. This research thus aimed at exploring the French female soccer players for the 20062007 season. We studied their birthdates distribution compared to the national standards. Moreover, we distinguished a sample of dropout players in order to examine whether their quarter of birth could account for this behaviour.

\section{A Systematic RAE}

Because a high competition between players and the prevalence of physical attributes for performance have been pointed out as necessary conditions for a RAE to occur (Musch \& Grondin, 2001), we expected a significant RAE to emerge among youth categories, as was observed for French basketball players by Delorme and Raspaud (2009). Conversely, because a very weak effect appeared for 17-year American soccer players (Vincent \& Glamser, 2006) and no effect at all was observed for French soccer players in the national championship (Delorme, Boiché \& Raspaud, in press), we posited that there should be no significant effect for the adult category.

These hypotheses were partially supported since a significant distortion emerged between the observed distribution by quarter and the national distribution for all age categories, including adults. The distortion observed among youth players respect the traditional RAE, with players born in Q1 and Q2 over-represented, and players born in Q3 and Q4 under-represented. This result echoes those obtained in basketball by Delorme and Raspaud (2009) and reinforce the idea that such phenomenon particularly arises in popular 
team sports involving physical contact. On the other hand, the significant effect obtained for adults contrasts with past literature in this activity with female samples (Vincent \& Glamser, 2006; Delorme, Boiche \& Raspaud, in press). Even if the pattern is less clear than for youth categories, the main irregularities observed go in the sense of a RAE, with a very important over-representation of players born in Q2 and a very marked under-representation of players born in Q4.

Moreover, it should be outlined that in the two past studies conducted on female soccer, the participants were elite players involved in the national championship, whereas the sample of the current study includes players of all levels. Given the size of this sample, which include the whole French female soccer players, one can reasonably think that it represents an 'average' level. In this vein, the systematic RAE noticed in this study disappears in the French female elite level where Delorme, Boiché and Raspaud (in press) did not find any RAE. Contrary to males among who the elevation of the level of practice was found to enhance the magnitude of the RAE (Musch \& Grondin, 2001), it looks like among females, the higher the level, the lower the RAE is. A social explanation seems necessary to justify this apparently paradoxical result.

As suggested by Vincent and Glamser (2006), social pressures that encourage adolescents to conform to gender-based stereotypes could prevent females from achieving excellence in competitive sport, especially early maturing females. The physical characteristics needed for athletic accomplishment are sometimes opposite to the representation of the ideal female body, which shall be thin and tiny (Choi, 2000). Shakib (2003) noted that the consequence of such opposition may be for some girls to drop out from sports at some point during puberty. Thus, such role conflicts could lead outstanding female players to drop out from soccer or to renounce to an elite practice. Because of the physical differences due to relative age, those pressures and the embarrassment associated should be 
particularly high for players born at the beginning of the year, which may explain why the birthdates distribution reveals no RAE among elite players. In brief, if an early physical development acts as an important advantage for young males in many sports, it also acts as a

socially constructed disadvantage for young females which could facilitate their dropout from sports activities.

Nevertheless, this interpretation remains speculative, and more research is needed to specifically examine if among female players involved at a good level of practice, there are actually more dropout among those born at the beginning of the competitive year, compared to those born in the last quarter.

\section{A Dual Mechanism resulting in RAE}

The second purpose of the study was to examine whether the birthdates distribution of females players who dropped out from soccer would significantly differ from the values observed in the whole sample of licensed players. Because of the physical inferiority occasioned by relative age, and the potential reduced opportunities to play and lowered selfperceptions, we hypothesised the dropout players to be over-represented in the last two quarters of the competitive year, and those born during the first two quarters to be underrepresented. Because this phenomenon may cease with physical growth, we set this hypothesis only for youth categories, and expected no significant effect among adults.

This hypothesis was partially supported, since in three age categories (less than 10, 14 and 17 years), the players born in the last 6 months of the competitive year were overrepresented, whereas those born in the first 6 months were under-represented, in the dropout sample. The reverse asymmetry observed in the global population (in fact, the classical RAE distribution) would thus partly be due to this unequal distribution of dropouts. A fruitful perspective of research would be to verify if the factors cited earlier (e.g., opportunities to 
play and self-perceptions) can actually be considered as mechanisms through which more important dropout rates are obtained among players born in Q3 and Q4.

It should also be underlined that in spite of an homogeneous distribution of dropout players in the less than 8 and less than 12 sub-groups, those categories were subject to a significant RAE. In other words, girls born in Q1 and Q2 are more prone to begin to play soccer, compared to their younger counterparts. Those born in Q3 and Q4, potentially because of their less advantaging physical attributes, show a kind of "self-selection" process before even trying the activity. The RAE can thus be seen as the result of two simultaneous phenomena. On the one hand, children born at the end of a competitive year would be less likely to undertake the practice of an activity in which weight, height or strength can be seen relevant for performance. On the other hand, those who begin to practice are more likely to drop out from it, and have fewer chances to be selected and to reach the elite.

\section{Perspectives}

Based on the whole population of the French Soccer Federation players for the 20062007 season, this study investigated in a diachronic perspective the RAE among females. A significant RAE was observed for all categories, suggesting that this effect seems decrease with level among females, contrary to what was observed among males. Besides, the analysis of the birthdates distribution suggests that this phenomenon results from a dual mechanism: a higher rate of dropout among players born late in the competitive year, and a bigger proportion of players born early in the competitive year among beginners.

Those results demonstrate the importance for RAE research to conduct more studies on female athletes, who remain neglected to date. The contradictory results obtained in the rare studies involving female participants show that the current knowledge on the mechanisms explaining the presence or absence of RAE still needs to be improved. 


\section{References}

Barnsley RH, Thompson AH, Barnsley PE. Hockey success and birthdate: The RAE. Canadian Association for Health, Physical Education and Recreation 1985: 51: 23-28.

Barnsley RH, Thompson AH. Birthdate and success in minor hockey: The key to the NHL. Canadian Journal of Behavioral Science 1988: 20: 167-176.

Baxter-Jones A. Growth and development of young athletes. Should competition levels be age related? Sports Med 1995: 20: 59-64.

Baxter-Jones A, Helms P. Effects of training at young age: a review of the Training of Young Athletes (TOYA) study. Pediatrics Exercise Science 1996: 8: 310-327.

Baxter-Jones A, Helms P, Maffull N, Baines-Preece J, Preece M. Growth and development of male gymnasts, swimmers, soccer and tennis players: A longitudinal study. Ann Hum Biol 1995: 22: 381-394.

Bisanz J, Morrison F, Dunn M. Effects of age and schooling on the acquisition of elementary quantitative skills. Dev Psychol 1995: 31: 221-236.

Choi PYL. Femininity and the physically active woman. London: Routledge, 2000.

Daniel TE, Janssen CTL. More on the relative age effect. Canadian Association for Health, Physical Education and Recreation 1987: 53: 21-24.

Delorme N, Boiché J, Raspaud M. The relative age effect in elite sport: The French case. Res Q Exerc Sport. In press.

Delorme N, Raspaud M. The relative age effect in French youth basketball: A study on the whole population. Scand J Med Sci Sports 2009: 19: 235-242.

Edgar S, O'Donoghue P. Season of birth distribution of elite tennis players. J Sports Sci 2005: 23: $1013-1020$.

Grondin S, Deshaies P, Nault LP. Trimestres de naissance et participation au hockey et au volleyball. La Revue Québécoise de l'Activité Physique 1984: 2: 97-103.

Grondin S, Trudeau F. Date de naissance et ligue nationale de hockey : Analyses en fonction de différents paramètres. STAPS. Revue des Sciences et Techniques des Activités Physiques et Sportives 1991: 26: 37-45.

Guillet E, Sarrazin P, Carpenter PJ, Trouilloud D, Cury F. Predicting persistence or withdrawal in female handballers with social exchange theory. International Journal of Psychology 2002: 37: 92-104.

Guillet E, Sarrazin, P, Fontayne, P, Brustad, RJ. Understanding female sport attrition in a stereotypical male sport within the framework of Eccles' expectancy-value model. Psychology of Woman Quarterly 2006: 30: 358-268. 
Helsen WF, Van Winckel J, Williams MA. The relative age effect in youth soccer across Europe. J Sports Sci 2005: 23: 629-636.

Jullien H, Turpin B, Carling C. Influence de la date de naissance sur la carrière professionnelle des joueurs de football français. Science \& Sports 2008: 23: 149-155.

Malina RM. Physical growth and biological maturation of young athletes. Exerc Sport Sci Rev 1994: 22: 389-434.

Malina RM, Bouchard C, Bar-Or O. Growth, maturation, and physical activity. Champaign : Human Kinetics, 2004.

Musch J, Grondin S. Unequal competition as an impediment to personal development: A review of the Relative Age Effect in Sport. Developmental Review 2001: 21: 147-167.

Musch J, Hay R. The relative age effect in soccer: Cross-cultural evidence for a systematic discrimination against children born late in the competition year. Sociology of Sport Journal 1999: 16: 54-64.

Ommundsen Y, Vaglum P. The influence of attributional style on the soccer-related selfesteem and persistence in soccer of young boys. Scand J Med Sci Sports 1991a: 1: 45-50.

Ommundsen Y, Vaglum P. The influence of low perceived soccer and social competence on later dropout from soccer: a prospective study of young boys. Scand J Med Sci Sports 1991b: 1: $180-188$.

Shakib S. Female Basketball Participation. Negotiating the Conflation of Peer Status From Childhood Throught Puberty. American Behavioral Scientist 2003: 46: 1405-1422.

Simmons C, Paull GC. Season-of-birth bias in association football. J Sports Sci 2001: 19: 677-686.

Tanner JM, Whitehouse RH. Clinical longitudinal standards for height, weight, height velocity and weight velocity and the stages of puberty. Arch of Dis Child 1976: 51: 170-178.

Vaeyens R, Philippaerts RM, Malina RM. The relative age effect in soccer: a match-related perspective. J Sports Sci 2005: 23: 747-756.

Van Rossum JHA. Relative age effect revisited: Findings from the dance domain. Percept Mot Skills 2006: 102: 302-308.

Vincent J, Glamser FD. Gender differences in the relative age effect among US Olympic Development Program youth soccer players. J Sports Sci 2006: 24: 405-414.

Ward P, Williams AM. Perceptual and cognitive skill development in soccer: The multidimensional nature of expert performance. Journal of Sport and Exercise Psychology 2003: 25: 93-111.

Wattie N, Baker J, Cobley S, Montelpare WJ. A historical examination of relative age effects in Canadian hockey players. International Journal of Sport Psychology 2007: 38: 178-186. 
Williams AM. Perceptual skill in soccer: Implications for talent identification and development. J Sports Sci 2000 : 18: 737-740. 
Table 1. Distribution of French female soccer players (2006-2007).

\begin{tabular}{|c|c|c|c|c|c|c|c|}
\hline Category & Q1 & Q2 & Q3 & Q4 & Total & $\chi^{2}$ & $P$ \\
\hline $\begin{array}{l}\text { Adults } \\
(\Delta)\end{array}$ & $\begin{array}{l}5,425 \\
(-168)\end{array}$ & $\begin{array}{c}5,905 \\
(+434)\end{array}$ & $\begin{array}{l}5,748 \\
(+91)\end{array}$ & $\begin{array}{l}5,686 \\
(-357)\end{array}$ & 22,764 & 62.14 & $<.0001$ \\
\hline $\begin{array}{l}\text { Under } 17 \\
(\Delta)\end{array}$ & $\begin{array}{l}2,154 \\
(+26)\end{array}$ & $\begin{array}{l}2,338 \\
(+106)\end{array}$ & $\begin{array}{l}2,208 \\
(-54)\end{array}$ & $\begin{array}{l}2,084 \\
(-78)\end{array}$ & 8,784 & 9.54 & $<.05$ \\
\hline $\begin{array}{c}\text { Under } 14 \\
(\Delta)\end{array}$ & $\begin{array}{l}1,450 \\
(+114)\end{array}$ & $\begin{array}{l}1,478 \\
(+45)\end{array}$ & $\begin{array}{l}1,429 \\
(-18)\end{array}$ & $\begin{array}{l}1,259 \\
(-141)\end{array}$ & 5,616 & 25.50 & $<.0001$ \\
\hline $\begin{array}{c}\text { Under } 12 \\
(\Delta)\end{array}$ & $\begin{array}{c}1,860 \\
(+8)\end{array}$ & $\begin{array}{l}2,058 \\
(+102)\end{array}$ & $\begin{array}{l}1,968 \\
(-38)\end{array}$ & $\begin{array}{l}1,888 \\
(-72)\end{array}$ & 7,774 & 8.72 & $<.05$ \\
\hline $\begin{array}{l}\text { Under } 10 \\
(\Delta)\end{array}$ & $\begin{array}{l}1,938 \\
(+133)\end{array}$ & $\begin{array}{l}2,023 \\
(+118)\end{array}$ & $\begin{array}{l}1,896 \\
(-42)\end{array}$ & $\begin{array}{l}1,663 \\
(-209)\end{array}$ & 7,520 & 41.35 & $<.0001$ \\
\hline $\begin{array}{c}\text { Under } 8 \\
(\Delta)\end{array}$ & $\begin{array}{l}1,495 \\
(+190)\end{array}$ & $\begin{array}{l}1,446 \\
(+82)\end{array}$ & $\begin{array}{l}1,331 \\
(-78)\end{array}$ & $\begin{array}{l}1,162 \\
(-195)\end{array}$ & 5,434 & 64.58 & $<.0001$ \\
\hline $\begin{array}{c}\text { Total U8-U17 } \\
(\Delta)\end{array}$ & $\begin{array}{l}8,897 \\
(+472)\end{array}$ & $\begin{array}{l}9,343 \\
(+415)\end{array}$ & $\begin{array}{l}8,832 \\
(-202)\end{array}$ & $\begin{array}{l}8,056 \\
(-685)\end{array}$ & 35,128 & 103.92 & $<.0001$ \\
\hline
\end{tabular}

Note: $\Delta$ is the difference between the observed distribution and the theoretical expected distribution. 
Table 2. Dropout in French female soccer (2006-2007).

\begin{tabular}{lccc}
\hline Category & Total & Dropout & $\%$ \\
\hline Adults & 22,764 & 6,743 & 29.62 \\
Under 17 & 8,784 & 2,404 & 27.37 \\
Under 14 & 5,616 & 1,689 & 30.07 \\
Under 12 & 7,774 & 2,159 & 27.77 \\
Under 10 & 7,520 & 1,686 & 22.42 \\
Under 8 & 5,434 & 604 & 11.12 \\
\hline Total & 57,892 & 15,285 & 26.40 \\
\hline
\end{tabular}


Table 3. Distribution of dropout in French female soccer (2006-2007).

\begin{tabular}{|c|c|c|c|c|c|c|c|}
\hline Category & Q1 & Q2 & Q3 & Q4 & Total & $\chi^{2}$ & $P$ \\
\hline Adults & 1,547 & 1,747 & 1,770 & 1,679 & 6,743 & 4.92 & $<.18$ \\
\hline$(\Delta)$ & $(-60)$ & $(-2)$ & $(+67)$ & $(-5)$ & & & \\
\hline Under 17 & 568 & 612 & 679 & 545 & 2,404 & 12.33 & $<.01$ \\
\hline$(\Delta)$ & $(-21)$ & $(-28)$ & $(+74)$ & $(-25)$ & & & \\
\hline Under 14 & 412 & 414 & 441 & 422 & 1,689 & 8.72 & $<.05$ \\
\hline$(\Delta)$ & $(-24)$ & $(-31)$ & $(+11)$ & $(+44)$ & & & \\
\hline Under 12 & 536 & 579 & 557 & 487 & 2,159 & 3.66 & $<.30$ \\
\hline$(\Delta)$ & $(+19)$ & $(+8)$ & $(+10)$ & $(-38)$ & & & \\
\hline Under 10 & 402 & 458 & 395 & 431 & 1,686 & 13.71 & $<.01$ \\
\hline$(\Delta)$ & $(-33)$ & $(+4)$ & $(-30)$ & $(+58)$ & & & \\
\hline Under 8 & 176 & 168 & 146 & 114 & 604 & 2.70 & $<.44$ \\
\hline$(\Delta)$ & $(+10)$ & $(+7)$ & $(-2)$ & $(-15)$ & & & \\
\hline Total U8-U17 & 2,094 & 2,231 & 2,218 & 1,999 & 8,542 & 3.05 & $<.38$ \\
\hline$(\Delta)$ & $(-4)$ & $(-14)$ & $(+64)$ & $(-46)$ & & & \\
\hline
\end{tabular}

Note: $\Delta$ is the difference between the observed distribution and the theoretical expected distribution. 